\title{
The development of determiners in the context of French-English bilingualism: a study of cross-linguistic influence*
}

\author{
Coralie HERVÉ \\ University of Essex, $U K$
}

AND

Ludovica SERRATRICE

University of Reading, $U K$

(Received 27 April 2016-Revised 3 February 2017-Accepted 15 September 2017-First published online Io November 20I7)

\section{ABSTRACT}

This paper reports the preliminary results of a study examining the role of structural overlap, language exposure, and language use on crosslinguistic influence (CLI) in bilingual first language acquisition. We focus on the longitudinal development of determiners in a corpus of two French-English children between the ages of 2;4 and 3;7. The results display bi-directional CLI in the rate of development, i.e., accelerated development in English and a minor delay in French. Unidirectional CLI from English to French was instead observed in the significantly higher rate of ungrammatical determiner omissions in plural and generic contexts than in singular specific contexts in French. These findings suggest that other language-internal mechanisms may be at play. They also lend support to the role of expressive abilities on the magnitude of this phenomenon.

\section{Theoretical background}

Although bilingual children's linguistic development largely follows the path of monolinguals (De Houwer, 2009), there is ample evidence that bilinguals' linguistic behaviour may occasionally differ from a quantitative and/or

[*] Address for correspondence: Coralie Hervé, University of Essex-Department of Language and Linguistics, Wivenhoe Park, Colchester $\mathrm{CO}_{4}{ }_{3} \mathrm{SQ}$, United Kingdom. e-mail: c.herve@essex.ac.uk 
qualitative standpoint from that of monolingual children. This phenomenon is known as cross-linguistic influence (CLI), i.e., delay, acceleration, transfer (Paradis \& Genesee, I996). In the past two decades, research on the determinants of CLI has picked up momentum. Hulk and Müller (2000) were the first to formulate specific predictions. CLI would affect linguistic phenomena that exhibit (i) a degree of structural overlap at the surface level, i.e., structures existing in the two languages but exhibiting different grammatical analyses, and (ii) structures that are at the interface between two modules of grammar in the so-called C-domain, i.e., syntax-pragmatics (Hulk \& Müller, 2000, pp. 228-9). Subsequent research reported instances of CLI after the instantiation of the C-system (Serratrice, Sorace, \& Paoli, 2004), as well as outside of the syntax-pragmatics interface (syntax-semantics interface: Fernández Fuertes \& Liceras, 2010; Liceras, Fuertes, \& de la Fuente, 2012; Serratrice, Sorace, Filiaci, \& Baldo, 2009; narrow-syntax structures: Argyri \& Sorace, 2007). This led recent investigations to consider the role of additional language-internal (e.g., language processing) and language-external variables (e.g., language dominance) in CLI.

Adopting a psycholinguistic approach, Nicoladis (2006) frames CLI in terms of an epiphenomenon of speech production resulting from the co-activation of a bilingual speaker's two languages at the lemma level. In two-step models of speech production, the lemma level is where lexical entries are retrieved from the mental lexicon with the relevant grammatical features (e.g., word class, gender) and the associated combinatorial nodes, i.e., the syntactic structures into which words fit. Nicoladis thus proposes a processing account for word order reversals in $\operatorname{Adj}+\mathrm{N}$ and $\mathrm{N}+\mathrm{Adj}$ word order in French-English bilingual children. The activation of a word (apple) and an adjective (green) in English will activate the associated English $\mathrm{Adj}+\mathrm{N}$ word order. At the same time, for a French-English bilingual, the translation equivalents (pomme) and (vert) will also be co-activated, albeit to a lesser extent, together with the French $\mathrm{N}+\mathrm{Adj}$ word order. Co-activation of these structures may lead to CLI when the competition is won by the structure of the non-target language, i.e., the French word order when the speaker is using English words in an English context. One of the predictions arising from this processing account is that CLI would be facilitated via syntactic priming by prior exposure and/or use of a given structure (Nicoladis, 2006, Serratrice, 2007).

Recent experiments provide empirical evidence for the co-activation of syntactic structures across bilingual children's languages and for the role of cross-linguistic syntactic priming $(\mathrm{Adj}+\mathrm{N}$ word order in SpanishEnglish: Hsin, Legendre, \& Omaki, 2013; left-dislocations in FrenchEnglish: Hervé, Serratrice, \& Corley, 20ı6; passive constructions in Spanish-English: Vasilyeva, Waterfall, Gamez, Gomez, Bowers, \& Shimpi, 2010). Crucially, Hsin et al. (2013) showed that syntactic 768 
constructions are shared across languages even in the absence of structural overlap, as Spanish-English children were successfully primed to use the English Adj $+\mathrm{N}$ word order in Spanish, a language in which the canonical word order for adjectives is post-nominal. Hervé et al. (2016) indicated that bilingual children are sensitive to the frequency of syntactic structures in their input as language exposure affected the likelihood of producing a left-dislocation in both optimal (French) and sub-optimal (English) discourse contexts. Overall, the processing account considers the possibility of bi-directional CLI in any language combination as a result of the interaction between the two competing linguistic systems. The degree of co-activation would depend on, among other things, the frequency of the target structure in the input. This model successfully accounts for previous instances of CLI in the presence/absence of overlap as well as outside of the interface condition.

Determiners in French and English. Significant cross-linguistic differences exist in the way Romance and Germanic languages encode NPs. Chierchia (I998) formulated the Nominal Mapping Parameter (NMP) to characterise those differences according to the way nouns refer to kinds. Romance languages are assigned the [-arg, +pred] setting as all nouns are by default predicates; the projection of a determiner is required for a noun to appear in argument position. Germanic languages are given the $[+$ arg, + + pred] setting as nouns either denote a predicate or an argument. Nouns denoting a predicate are countable and need a determiner in argument position (e.g., I moved the chairs / * Chair is not a table). Nouns denoting kinds, i.e., referring to the totality of their instance (e.g., Advice is available online / *Advices are always welcomed) have a mass denotation and appear without a determiner in every syntactic position. The type shifting operation that applies to kind-referring nouns in Germanic languages to turn them into arguments in generic and non-specific contexts is interpreted in terms of economy considerations; it generates the appropriate semantic interpretation without the projection of a determiner, as is the case in Romance languages. French is the most restrictive Romance language as overt determiners are obligatory in argument position. In English, mass nouns (MNs) and indefinite plural nouns (IPs) occur without a determiner in non-specific contexts and generic contexts, whereas French relies on the use of partitive articles (i.e., $d u$, de la) in non-specific contexts and requires the use of a definite article to signal genericity.

CLI: the case of determiners. A few studies have shown that the simultaneous acquisition of determiners in a Romance-Germanic language 
pair is vulnerable to CLI (Granfeldt, 2000; Hulk, 2004; Kupisch, 2003, 2007; Serratrice et al., 2009). CLI may occur (i) from the Romance to the Germanic language as an early convergence on the target use of determiners in the Germanic language and/or transfer in the use of a definite article in generic contexts (e.g., Les chiens sont des mammifères / *The dogs are mammals); (ii) from the Germanic to the Romance language as a prolonged Bare Noun (BN) phase in the Romance language and/or transfer in the use of IPs and MNs in non-specific (e.g., I want cereals/ milk vs. *fe veux (des) céréales / (du) lait) and in generic contexts (e.g., I like chocolate/sweets vs. *Y'aime (le) chocolat / (les) bonbons). Corpus-based analyses have examined the presence/absence of determiners in specific and non-specific contexts in early development. Kupisch (2003) observed a heterogeneous determiner developmental pattern in the corpus of two French-German bilinguals aged I;I-4;0 (Céline) and 2;2-2; I I (Alexander). While one child, Alexander, did not show any evidence of CLI in French, the other child, Céline, showed a peculiar acquisition path. She went through a phase where she barely spoke French but developed German at a regular pace. Although the girl's use of German determiners was target-like from 2;4, early convergence on the target-stage in French was not observed once she started to use more French. Determiner omission was reported with MNs (e.g., et (du) sucre 'and sugar'; mais il va (le) café d'dans 'but it goes coffee in it-coffee goes inside this'). Kupisch argued that these occurrences could not be interpreted as transfers from German since she considered the error-rate for MNs to be too low, i.e., 26.9\%; especially given that IPs were unaffected. Her point was that both MNs and IPs should be affected if these instances were cross-linguistic transfers. Subsequently, Kupisch (2007) re-considered CLI in the use of determiners in four ItalianGerman children aged I;6-3;0: an Italian-dominant child, two balanced children, a German-dominant child. Language dominance was established by measuring the children's productive abilities, i.e., MLUw, Upper Bound, and increase in lexicon size. In Italian, three bilinguals exhibited a slightly delayed determiner development in comparison to monolinguals, but the difference with monolinguals decreased with growing dominance in Italian. In German, all the children showed an accelerated development in comparison to the German monolinguals. However, the Germandominant child's development was just halfway between the fastest and the slowest German learners. Moreover, the effect in Italian was not as strong as the acceleration in German. Kupisch argued that CLI would only occur if the dominant language could facilitate the acquisition of a specific grammatical form. In the specific instance of German and Italian, the latter is the structurally less complex language as it always requires the projection of a determiner in argument position, as opposed to German. 
Two experimental studies have so far supplemented these corpus studies on CLI by examining older bilingual children's interpretation of the presence/absence of a determiner in connection with a specific/generic reading (Kupisch \& Pierantozzi, 2010; Serratrice et al., 2009). Serratrice et al. (2009) examined the effect of structural complexity, typological relatedness, the language of the home-country, and age on the CLI of determiners in English-Italian and Spanish-Italian bilinguals aged 6;2Iо; IO. In Italian, response accuracy was at ceiling for the monolingual adults and children, and for the Italian-Spanish children. In contrast, the English-Italian bilinguals accepted significantly more ungrammatical BNs in generic contexts in Italian than all other groups. The language of the community, i.e., English vs. Italian, affected the English-Italian children's accuracy, which suggests that the frequency of syntactic structures in children's input affects the magnitude of CLI. Serratrice et al. (2009) also argued that the unidirectional CLI from English, the language with the most economical setting of the NMP, indicates that structural overlap is not always necessary for CLI to take place. Kupisch and Pierantozzi (2010) examined 6- to ro-year-old Italian-German bilingual children's interpretation of plural definite phrases (DPs) in a truth-value judgement task. In Italian, monolingual children and adults displayed a bias for the generic reading despite both specific and generic interpretations being grammatical, whereas the bilinguals accepted significantly fewer generic interpretations. These results suggest that the German association of plural DPs with specificity may have triggered this morphosyntactic-semantic association in Italian to a larger extent than in Italian monolinguals. In German, adults and monolingual and bilingual children all over-accepted target-deviant generic readings with plural DPs. This pattern decreased with age, suggesting that the morphological cues for the interpretation of specificity and genericity is acquired later in German. This unidirectional transfer from German to Italian is consistent with Serratrice et al.'s (2009) study where children would occasionally favour the more economical system of the Germanic language.

Research questions and predictions. The picture that emerges from these studies is mixed with regard to the role of language-internal factors and language dominance. The aims of the present study are to (i) consider the role of structural overlap, i.e., overt determiners in French vs. overt determiners and BNs in English, and economy constraints (NMP), as well as to (ii) address the role of language dominance on CLI by considering dominance in terms of both language exposure, i.e., input quantity, and language use, i.e., productive abilities as a percentage of the total number of French, English, and mixed utterances produced in each session. This 
approach contrasts with previous studies which only considered dominance in terms of input without taking into account output as well. The specific focus is on the use of determiners in the longitudinal corpus of a language-pair, French-English, that has not been previously investigated in connection with determiner use.

If structural overlap and productive abilities govern CLI of determiners (Kupisch, 2007), then (i) a balanced French-English child may exhibit accelerated development in English due to the less complex French determiner system, and hence we predict acceleration in the acquisition of determiners in English; (ii) an English-dominant child would not display any evidence of CLI; and (iii) CLI should only occur from the language with one grammatical option to the language with two options, i.e., from French to English in the form of target-deviant definite articles in generic contexts in English.

In contrast, if the NMP's economical setting of English [ + arg, +pred] constrains the CLI of determiners (Serratrice et al., 2009), the FrenchEnglish children should omit French determiners with MNs and IPs in non-specific and generic contexts. However, this account makes no predictions with respect to the acceleration of determiner development due to CLI from the Romance to the Germanic language.

If CLI is the result of processing mechanisms through syntactic priming by prior exposure/use of a given structure (Nicoladis, 2006; Serratrice, 2007), then this phenomenon should occur bi-directionally from French to English and/or from English to French as a function of language dominance.

As for dominance, if expressive abilities affect CLI of determiners (Kupisch, 2007), then variations in the magnitude of CLI should exist between the balanced and the English-dominant child of this corpus. On the contrary, if language exposure plays a role on the magnitude of CLI (Serratrice et al., 2009), then comparable direction and amplitude of CLI should be observed given our bilinguals' comparable exposure to French and English.

\section{Method}

The data. This study examines the emergence and use of determiners in argument Noun Phrases (NPs) in the speech of two French-English bilingual children from the Hervé corpus collected by the first author. The two children, Anne and Sophie, were video-recorded monthly over twelve months in their family homes. Neither the children nor the parents were given any specific instructions on the language to use during the filming sessions; they interacted freely with their French-speaking mother or their English-speaking father and English-speaking child-minder during routine activities (i.e., playing, cooking, having a meal, etc.) in separate filming 
sessions. The children are both the offspring of cross-cultural marriages where the mother is a native French speaker and the father is a native English speaker. Both children were growing up in England and were regularly exposed to their two languages from birth. The corpus varies with respect to the number of recordings during the twelve-month period and with respect to the age span covered (see Table I). In order to maximize the amount of data analysed while still preserving a longitudinal approach, the children's French and English data were divided into two periods on the basis of their MLUw in each session.

This study does not include the collection of new corpora of monolingual data in English and French; for reference to monolingual development we refer to previously published evidence in the literature (see Prévost, 2009, for a thorough overview). The acquisition of articles in young Englishand French-speaking children has been studied both naturalistically (e.g., Bassano, I998; Bloom, I970; Brown, I973; Kupisch, 2003; Müller, I 994; Pine \& Lieven, I997) and experimentally (e.g., Garton, I983; KarmiloffSmith, I979; Maratsos, I974; Stevenson \& Sims, I993; Warden, I976).

Coding. The transcripts were searched for utterances that were (i) in the target language of the filming session - defined as the language used by the adult - and that (ii) contained a verb or an easily recoverable verb (e.g., Anne: $m y \operatorname{dog}$ (is) full now, i.e., meaning her dog has finished eating). The parents used their first language with the children, i.e., French for the mothers and English for the fathers, Anne's childminder did not know any French and used only English. Utterances were excluded from the data if they contained partially unintelligible material or direct repetitions of the input, if they were unfinished utterances, or if they occurred in singing or reading. All remaining utterances were coded at argument level as in Serratrice (2005). Determiners were classified into six categories: (i) indefinite articles (e.g., a dog / un chien); (ii) definite articles (e.g., the dog / le chien); and (iii) $\mathrm{BNs} /$ partitives (milk / du lait; dogs / des chiens), (iv) demonstratives (this dog / ce chien); (v) possessives (e.g., his dog / son chien); and (vi) quantifiers (all the dogs / tous les chiens). Rates of determiner omission in obligatory contexts, i.e., ungrammatical omissions (e.g., * (I) need $\varnothing$ t-shirt), were calculated by considering the total number of determiner omissions over the total number of contexts requiring a determiner. The infelicitous use of the dogs instead of dogs in a generic context was counted as a target-deviant definite article. Generic contexts were identified as a function of the previous discourse and topic of conversation. For example, in Sophie's utterance no shepherds don't do that to princesses, the referents shepherds and princesses do not refer to specific or non-specific persons but to characters in general. All examples were 
Table I

Overview of the bilingual corpus

\begin{tabular}{|c|c|c|c|c|c|}
\hline Language & Child & Age & No. of recordings & MLUw (mean) & No. of clauses \\
\hline \multirow[t]{4}{*}{ English } & Sophie & $2 ; 6-2 ; 10$ & 5 & $3 \cdot 52$ & 88 I \\
\hline & & $3 ; 0-3 ; 7$ & 6 & $4 \cdot 15$ & 1023 \\
\hline & Anne & $2 ; 4-2 ; 7$ & 3 & $\mathrm{I} .75$ & I 58 \\
\hline & & $2 ; 8-3 ; 4$ & 8 & $3 \cdot 35$ & I 248 \\
\hline \multirow[t]{4}{*}{ French } & Sophie & $2 ; 6-2 ; 9$ & 4 & 3. I I & 570 \\
\hline & & $2 ; 10-3 ; 7$ & 8 & 3.80 & 1052 \\
\hline & Anne & $2 ; 4-2 ; 7$ & 4 & I. $8 \mathrm{I}$ & I I 7 \\
\hline & & $2 ; 8-3 ; 2$ & 7 & $2.5^{2}$ & 95 \\
\hline
\end{tabular}

coded independently by both authors and agreement reached $93 \%$ after the resolution of discrepancies.

\section{Establishing language dominance}

Language exposure. Cattani et al.'s (2014) parental questionnaire was used to document the children's language exposure and use within their familial and social environments. Exposure to English was estimated to be around $55 \%$ for Anne, and around $58 \%$ for Sophie between the ages of $2 ; 6$ and 3;3. Sophie's exposure shifted towards more English (65\%) from 3;4 as she started attending pre-school. Throughout most of the data collection, the two children had a fairly balanced $(40 \%<\mathrm{X}<60 \%)$ exposure to their two languages (Cattani et al., 2014).

Language use. Figures I-4 report a breakdown of the children's use of French, English, and mixed language utterances in the French and the English sessions. These percentages were calculated as a percentage of the number of French, English, and code-switched utterances in each recording session. Figures $\mathrm{I}$ and 2 reveal a strong discrepancy in Anne's language use. In the English contexts (Figure I), Anne's use of French is scarse and decreases with time. As for the French contexts (Figure 2), from 2;5 Anne entered a phase in which she became gradually reluctant to speak French and favoured the use of English independently of the context.

Figures 3 and 4 show Sophie's higher propensity to use code-switching in French than in English contexts. In addition, Sophie uses English over 95\% of the time in nearly all the English sessions, whereas she speaks French only $70 \%$ of the time in French contexts, with the exception of two sessions at 3;0 and 3; I where the child preferred using English and used French only about 
DETERMINER DEVELOPMENT IN FRENCH-ENGLISH CHILDREN

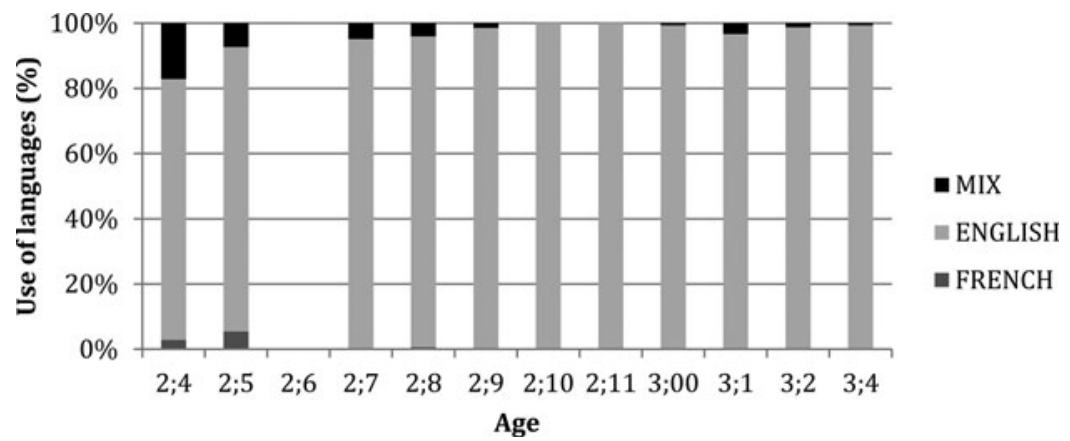

Fig. I. Language use in Anne's English sessions.

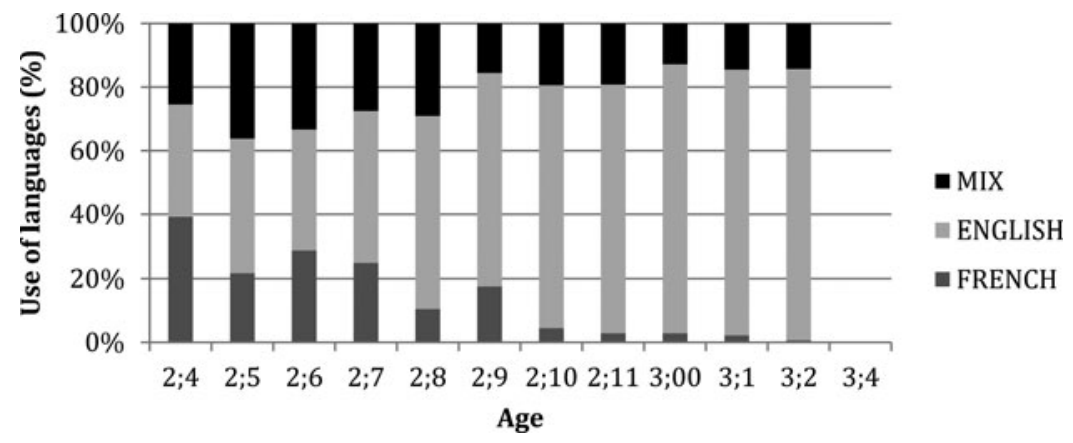

Fig. 2. Language use in Anne's French sessions.

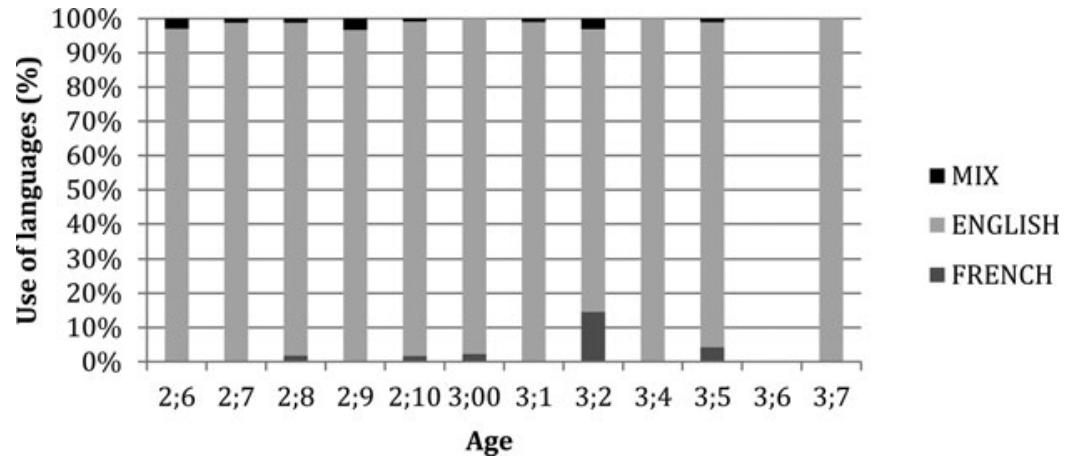

Fig. 3. Language use in Sophie's English sessions. 


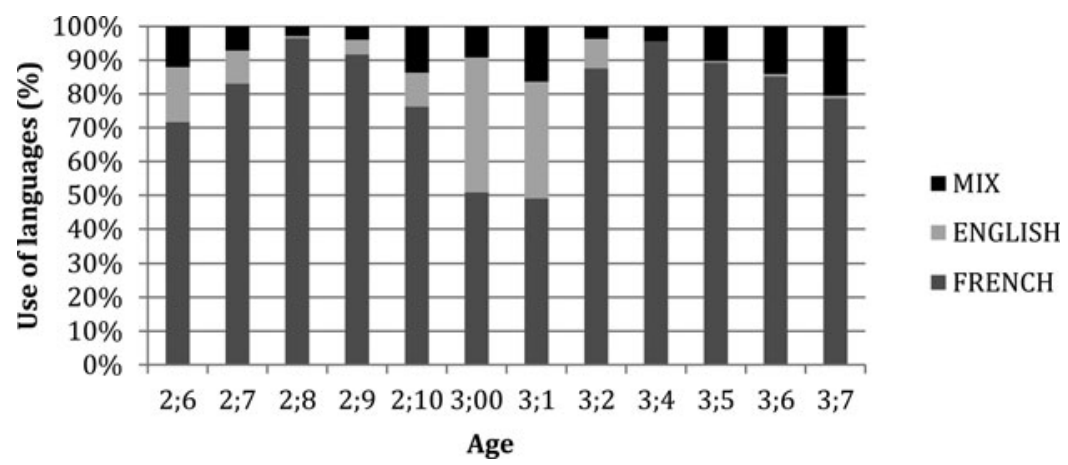

Fig. 4. Language use in Sophie's French sessions.

$50 \%$ of the time. This pattern indicates a tendency towards greater use of English regardless of the language of interaction.

Overall, Sophie appears to be a fairly balanced child with a slight dominance in English, while Anne, who receives comparable exposure to English and French, displays a much stronger preference for English in her own language use.

\section{Results}

\section{CLI: acceleration/delay}

Emergence of target-like determiners. Table 2 reports the bilingual children's production of target-like determiners in argument NPs in English and French. At 2;6, Sophie already has a good command of the determiner system in her two languages as she uses felicitous definite and indefinite articles as well as demonstratives, possessives, quantifiers, and BNs in both. Despite Anne's slower linguistic development, she also produces a variety of determiners between 2;4 and 2;7. In contrast to Brown's (1973) naturalistic analysis of determiner development in English-speaking children, Anne's production of definite and indefinite articles does not seem to emerge at the same time. Her first use of a definite article is observed at 2;5, while her first indefinite article is observed at 2;7. This pattern of emergence resembles what is commonly observed in French-speaking children (Prévost, 2009). Contrary to what has been shown for English-speaking children (Abu-Akel, Bailey, \& Thum, 2004), Anne's production of definite and indefinite articles is not equally distributed by the age of 2;6. Between 2;8 and 3;4, Anne's production of articles rises sharply. Indefinites become prevalent over definites. She also uses a considerable number of BNs, possessives/ quantifiers, and a few demonstratives. In French, Anne consistently uses 
Table 2

Total number of target-like determiners produced in argument position in the bilingual data

\begin{tabular}{|c|c|c|c|c|c|c|c|c|c|}
\hline Lang. & Child & Age & MLUw (mean) & Indef. $(\%)$ & Def. (\%) & BN / Part-IP (\%) & $\operatorname{Dem}(\%)$ & Poss $(\%)$ & Quant (\%) \\
\hline \multirow[t]{4}{*}{ English } & Sophie & $2 ; 6-2 ; 10$ & $3 \cdot 52$ & $45(23)$ & $42(2 \mathrm{I})$ & I6 (8) & $4(2)$ & I9 (IO) & $70(36)$ \\
\hline & & $3 ; 0-3 ; 7$ & 4. 15 & 35 (I7) & $5^{\mathrm{I}}(25)$ & I $5(7)$ & I $2(6)$ & $50(25)$ & $4 \mathrm{I}(20)$ \\
\hline & Anne & $2 ; 4-2 ; 7$ & $\mathrm{I} .75$ & I (6) & I I $(65)$ & I (6) & I (6) & I (6) & $2(\mathrm{II})$ \\
\hline & & $2 ; 8-3 ; 4$ & $3 \cdot 35$ & $52(\mathrm{I} 8)$ & 29 (IO) & 33 (I I) & I9 (7) & $97(34)$ & $57(20)$ \\
\hline \multirow[t]{4}{*}{ French } & Sophie & $2 ; 6-2 ; 9$ & 3. I I & $23(38)$ & I7 (28) & I I (I 8) & - & $4(7)$ & $5(8)$ \\
\hline & & $2 ; 10-3 ; 7$ & 3.80 & $43(3 \mathrm{I})$ & $37(27)$ & 26 (I9) & - & I 4 (IO) & I7（I3） \\
\hline & Anne & $2 ; 4-2 ; 7$ & I.8I & $6(33)$ & $7(39)$ & 2 (I I) & - & 2 (I I) & I (6) \\
\hline & & $2 ; 8-3 ; 2$ & 2.52 & $3(30)$ & $2(20)$ & I (IO) & I ( IO) & $2(20)$ & I (IO) \\
\hline
\end{tabular}

Notes. Lang.: language; Indef.: indefinite articles; Def.: definite articles; BN: Bare Nouns; Part.: partitives; IP: Indefinite plurals; Dem: demonstratives; Poss: possessives; Quant.: quantifiers. 
definite and indefinite articles and other determiners between 2;4 and 2;7. These findings are in line with research on French development (Bassano, I 998; Kupisch, 2003; Müller, I 994). From 2;8, Anne's decreasing use of French does not allow for an increase in the number of determiners. Despite Anne's limited production of French utterances and her dominance in English, she seems to have started the acquisition process of determiners slightly earlier in French than in English.

Determiner omission. Figure 5 compares the rate of determiner omission in obligatory contexts. In English, Sophie's rate of determiner omission oscillates between $6.7 \%$ and I I.3\% from $2 ; 6$, suggesting that her use is substantially target-like. Overall, Sophie appears to have reached $90 \%$ determiner provision in obligatory contexts 12 months before the age reported for English-speaking peers (Brown, I973). In French, Sophie's development is rather unexpected. Determiner omission rises from $10.4 \%$ to $18.9 \%$ across the two periods. This short rise does not reach significance $\left(X^{2}(\mathrm{I}, \mathrm{N}=236)=2.5 \mathrm{I}, p=. \mathrm{II}_{3}\right)$. However, a closer examination of the data reveals that determiner omission is fairly constant across data and constitutes at most from one to three occurrences for about 20 nominal references $(5 \%$ to $15 \%)$. The short rise of determiner omission is the result of two peaks that occur at 2; 10 (23\%) and between $3 ; 4$ and 3;5 $(40 \%)$, respectively. While the first peak at $2 ; 10$ is not significant $\left(X^{2}\left(\mathrm{r}, \mathrm{N}=\mathrm{I}_{0}\right)=\mathrm{I} .23, p=.268\right)$, the second at $3 ; 4-3 ; 5$ displays a significant omission peak $\left(X^{2}(\mathrm{I}, \mathrm{N}=\mathrm{I} 44)=6.63, p=.0 \mathrm{I}\right)$. From $3 ; 6$ onwards, Sophie reverts to target-like levels of determiner use. These two peaks come right after a period during which English was becoming particularly prevalent in her speech, which can be interpreted as temporarily affecting her determiner use in French.

In English, Anne omits fewer than 50\% of determiners in obligatory contexts from 2;4. Determiner omission decreases from $26.1 \%$ in the first period to $20 . \mathbf{1} \%$ in the second period. In fact, determiner omission decreases sharply to about I 5\% from 2; IO. Anne omits fewer than 10\% of determiners at 3;4. Overall, Anne displays an extremely short, if any, acceleration in the development of determiners as she converges on the target-production stage about two months ahead of English-speaking monolinguals who typically reach the target-stage at 3;6 (Brown, 1973). In contrast, determiner omission increases in French from $45.5 \%$ at $2 ; 5^{-2 ; 7}$ to $6 \mathrm{I} .5 \%$ at $2 ; 8-3 ; 2$. Determiner production remains optional throughout data collection. Her acquisition is thus delayed in comparison to French children who usually reach the target-stage by 2;6 (Bassano, I998). Interestingly, the rise of determiner omission may be considered as a precursor sign of Anne's declining production skills in French, as the 


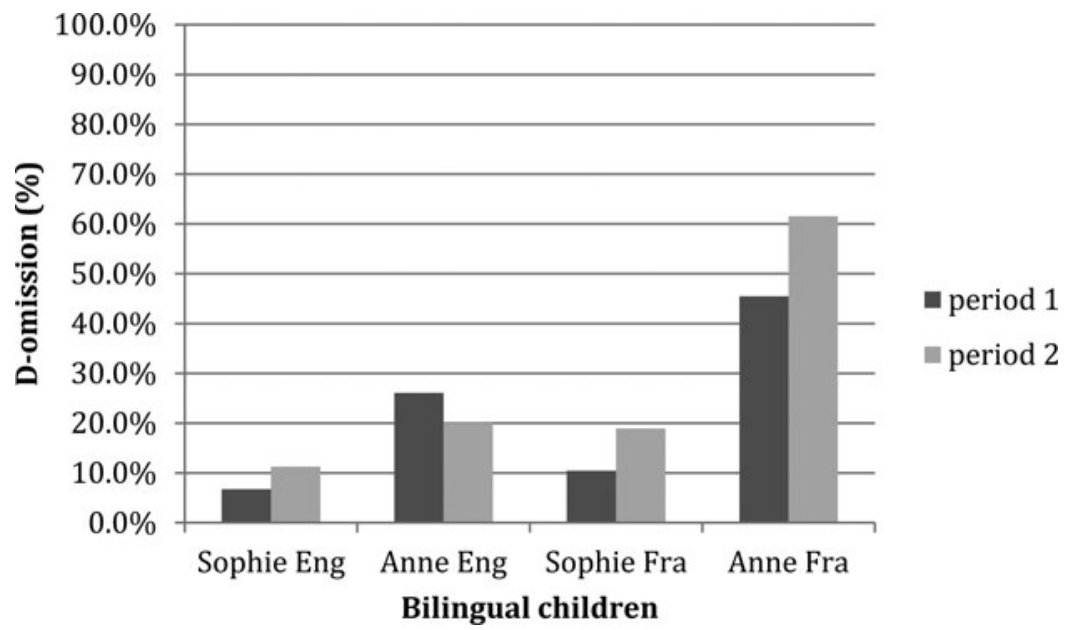

Fig. 5. Rate of determiner omission in argument position in the bilingual data.

number of omission doubles between 2;8 and 2;9, although the sharp drop in the total number of utterances produced in the French sessions occurs a month later when Anne is 2; Io (3 I vs. I4 utterances).

To conclude, the data suggest the existence of bi-directional CLI as illustrated by the children's accelerated determiner development in English and delayed acquisition in French.

Cross-linguistic influence in English: target-deviant definite articles in generic contexts. Table 3 summarizes the number and proportion of target-deviant definite articles in the bilinguals' English data. Sophie only produces two target-deviant definite articles that appear in front of MNs in non-specific contexts (e.g., No that stinks *the poo, while referring to the smell of the raclette cheese on her plate). Anne uses non-target the in indefinite contexts (4/8), and in non-specific contexts (I/8 mass noun; $2 / 8$ plural nouns), as well as in specific contexts ( $\mathrm{I} / 8$ possessive). These results provide additional empirical evidence supporting the literature on the late acquisition of the definite article, i.e., so-called egocentric error (De Cat, 20II, 20I3; Kail \& Hickmann, I 992; Schafer \& de Villiers, 2000), but are not conclusive as to the existence of systematic CLI from French to English.

Cross-linguistic transfers in French: determiner omission. Table 4 reports the number and proportion of determiner omissions in singular vs. plural and generic contexts in the bilinguals' French. Overall, Sophie is 
Table 3

Target-deviant determiners in argument position in the bilinguals' English data

\begin{tabular}{llccc}
\hline Language & Child & Age & MLUw ( (mean) & Def. (\%) \\
\hline English & Sophie & $2 ; 6-2 ; 10$ & 3.52 & $2 / 42(2)$ \\
& & $3 ; 0-3 ; 7$ & 4.15 & $0 / 50(0)$ \\
& Anne & $2 ; 4-2 ; 7$ & I.75 & I/I I (9) \\
& & $2 ; 8-3 ; 4$ & 3.35 & $7 / 29(24)$ \\
\hline
\end{tabular}

Note. Def.: definite articles.

significantly more likely to omit determiners in plural and generic contexts than in singular contexts $\left(X^{2}(\mathrm{I}, \mathrm{N}=20 \mathrm{I})=\mathrm{I} 5.75, p<.00 \mathrm{I}\right)$. Moreover, definite article omission declines with age, while the likelihood of omitting determiners in plural contexts increases between 2; 10 and 3;7. Specifically, 9/19 BNs in plural and generic contexts (i.e,. 5 in partitive contexts (I), 3 in IP contexts (2), I in a generic context (3)) occur at the age $3 ; 4$. The few other omissions in plural contexts appear at 3;5 after an English-dominant period with regard to Sophie's production.

(1) Tu as argent dans mon sac. you have money in my bag

(Sophie 2;10)

'You've got money in my bag.'

(2) Et toi aussi, tu veux rice-crispies, toi, Maman? and you too you want rice-crispies, you, Mummy

'Do you also want some rice-crispies Mummy?' (Sophie 3;4)

(3) Il aime thé.

(Sophie 3;4)

he likes tea

'He likes tea.'

Anne's French data contain infelicitous BNs in partitive (4) and IP (5) contexts. Finally, the only generic occurs without a determiner. Overall, Anne omits significantly higher rates of determiner in plural and generic contexts than in singular contexts $\left(X^{2}(\mathrm{I}, \mathrm{N}=54)=4.34, p=.04\right)$. Anne does not seem to have developed an independent grammatical system for partitives and IPs since she consistently produces BNs for IPs (8/8) and only uses the partitive determiner in half $(3 / 6)$ of the obligatory contexts. The limited available data prevent us from drawing firmer conclusions about generic contexts. 
Table 4

Determiner omission in singular, plural, and generic contexts in the bilinguals' French

\begin{tabular}{|c|c|c|c|c|c|c|c|}
\hline Lang. & Child & Contexts & Determiner type & Omitted & Realized & Total & $\%$ omission \\
\hline \multirow[t]{10}{*}{ French } & \multirow[t]{5}{*}{ Sophie } & \multirow[t]{2}{*}{ Plural } & Partitive & I 3 & I9 & 32 & $41 \%$ \\
\hline & & & Indef Plur. & 4 & I 4 & I 8 & $22 \%$ \\
\hline & & Generics & Definite & 2 & I & 3 & $67 \%$ \\
\hline & & \multirow[t]{2}{*}{ Singular } & Indefinite & 6 & 68 & 74 & $8 \%$ \\
\hline & & & Definite & I I & 63 & 74 & I $5 \%$ \\
\hline & \multirow[t]{5}{*}{ Anne } & \multirow[t]{2}{*}{ Plural } & Partitive & 3 & 3 & 6 & $50 \%$ \\
\hline & & & Indef Plur. & 8 & 0 & 8 & $100 \%$ \\
\hline & & \multirow{3}{*}{$\begin{array}{l}\text { Generics } \\
\text { Singular }\end{array}$} & Definite & I & ० & I & $100 \%$ \\
\hline & & & Indefinite & I & I I & I 2 & $8 \%$ \\
\hline & & & Definite & I 8 & 9 & 27 & $67 \%$ \\
\hline
\end{tabular}

Notes. Partitive: partitive contexts; Indef. Plurals.: Indefinite plural contexts; Indefinite: indefinite article contexts; Definite: definite article contexts.

(4) Fe veux mange(r) chocolat.

I want to-eat chocolate

'I want to eat chocolate.'

(5) Why@e monsieur put@e piques@in the floor? why man put sharp things in the floor 'Why does the man drop sharp things on the floor?' (Anne 2; ro)

BNs and verb type/token ratio in plural/generic contexts. In order to determine whether determiner omissions in plural and generic contexts in the children's French is lexically constrained, we examined the number of type/token BNs occurring in plural/generic contexts (Table 5). In both datasets, this type/token ratio varies around 0.5 , which implies that the transfers are limited to a small class of nouns.

Table 6 summarises the number of verb types/tokens appearing with infelicitous BNs in argument position in French. Sophie predominantly omits determiners with the verb vouloir 'want' in plural contexts and with the verb aimer 'like' in generic contexts. As for Anne, the three BNs in partitive contexts occur with three different verbs, but $7 / 8 \mathrm{BNs}$ in IP contexts appear with the verb avoir 'have'. Overall, target-deviant BNs in French occur with a small number of verb types in these three problematic contexts.

\footnotetext{
I See the Childes Database <https://childes.talkbank.org/> for transcription conventions.
} 
Table 5

Bare noun type/token ratio in each context in French

\begin{tabular}{lccc}
\hline Child & Indef. Plur. & Partitive/MN & Generics \\
\hline Sophie & $3 / 4$ & $7 / \mathrm{r} 3$ & $2 / 2$ \\
Anne & $4 / 8$ & $2 / 3$ & I/I \\
\hline
\end{tabular}

Notes. Indef Plur.: indefinite plural contexts; Partitive/MN: partitive / mass noun contexts; Generics: generic contexts.

Table 6

Number of verb (type/token) occurring with target-deviant BNs in French

\begin{tabular}{|c|c|c|c|c|}
\hline Child & Verbs & Indef. Plur. & Partitive & Generic \\
\hline \multirow[t]{4}{*}{ Sophie } & vouloir & $3 / 4$ & $12 / 13$ & _- \\
\hline & avoir & - & I/I 3 & - \\
\hline & mettre & $\mathrm{I} / 4$ & - & \\
\hline & aimer & - & - & $2 / 2$ \\
\hline \multirow[t]{6}{*}{ Anne } & avoir & $7 / 8$ & - & - \\
\hline & put & $\mathrm{I} / 8$ & _- & _- \\
\hline & like & - & - & - \\
\hline & eat & - & $I / 3$ & - \\
\hline & want & - & $\mathrm{I} / 3$ & - \\
\hline & do & _- & $1 / 3$ & $\mathrm{I} / \mathrm{I}$ \\
\hline
\end{tabular}

Notes. Indef. Plurals.: Indefinite plural contexts; Partitive: partitive contexts; Generic: generic contexts.

In sum, the bilinguals' English data do not provide any evidence of transfers from French to English, i.e., infelicitous definite articles in generic contexts in English. In contrast, the bilinguals' French data display significantly more determiner omissions in plural and generic contexts than in singular contexts, which suggests the presence of transfers from English to French. Crucially, this small number of non-target omissions appears to be lexically dependent and to occur when language use shows English dominance.

\section{General discussion}

The aim of this preliminary study was to investigate the extent to which structural overlap and economy considerations can predict CLI in the course of determiner development in a new language pair, i.e., FrenchEnglish. We also sought to refine the role of language dominance on the direction and magnitude of CLI by considering both language exposure and language use. 
Our data confirm that CLI reduces the incidence of the asymmetric rate of determiner development between Romance and Germanic languages (Kupisch, 2007). However, while Sophie shows a considerable acceleration in the acquisition of determiners in English, Anne's acceleration is far less robust, although her rates of provision are still higher than for her English-speaking peers. Indeed, Anne's target use of determiners in English resembles that of French monolinguals, i.e., production of definite before indefinite articles, and no equal distribution of definite and indefinite articles by 2;6 (see Prévost, 2009). Besides, Anne's relatively slow linguistic development in French and in English in comparison to Sophie, i.e., MLUw, Upper Bound, and lexical diversity, suggests that she may actually have acquired determiners slightly earlier than her monolingual peers.

The developmental pattern emerging in French appears to be less stable. Sophie demonstrates intermittent inconsistencies in the realisation of determiners at two time-points that appear straight after a period during which English was becoming prevalent in her speech in French contexts. The causal relationship of this overlap remains disputable, but is nonetheless reinforced by the parallelism between Anne's strong delay throughout the second observation period and her decreasing expressive abilities in French. Overall, we argue that our preliminary results point to the existence of a possible relationship between the delayed determiner development and the children's level of expressive abilities in French, which would imply that CLI would be, at least partly, determined by the children's overall level of expressive skills.

Unlike in previous corpus studies of determiner development (Kupisch, 2003, 2007), we report a small number of instances of cross-linguistic transfers. As in experiments with older bilinguals (Kupisch \& Pierantozzi, 2010; Serratrice et al., 2009), these instances occurred from the Germanic language, i.e., English, to the Romance language, i.e., French, but not the reverse. Importantly, they only appeared when the children displayed stronger expressive abilities in English, which raises the question as to whether language dominance as a measure of productive abilities affects the likelihood and the direction of cross-linguistic transfers at the determiner level (Kupisch, 2007). A further finding is that these transfers occurred with a small number of nouns and verbs.

The bi-directionality of CLI indicates that neither structural overlap nor economy considerations fully account for CLI at the determiner level, suggesting that other internal mechanisms may be at play. In contrast, our data indicate that the French and English determiner systems affect one another, both in terms of developmental rate and in terms of transfers of null determiners. Recent experimental evidence has shown that bilinguals' language systems are co-activated in the presence and absence of structural 
overlap (Hartsuiker \& Pickering, 2008; Hsin et al., 20I3; Vasilyeva et al., 20I0). Moreover, the frequency of grammatical constructions and language dominance would affect the degree of activation of a particular formfunction association, hence the likelihood of CLI (Hervé et al., 20r6). The lexically specific instances of CLI in our data suggest that the formfunction association of potentially high-frequency words, e.g., null determiner + chocolate, in the child's English may lead to the entrenchment of this ungrammatical association in French, e.g., *null determiner + chocolat instead of the correct form $d u+$ chocolat. Although the sampling limitation of our corpus does not allow us to directly verify this hypothesis, the lexical specificity of CLI at the determiner level is consistent with the language processing interpretation of CLI whereby the co-activation of two grammatical systems occasionally leads to interferences between the language-specific syntactic structures (Nicoladis 2006, 2012; Serratrice, 2007; Serratrice, Sorace, Filiaci, \& Baldo, 2012). If this is the case, our results indicate that the degree of activation of the language-specific form-function association would also be to a certain extent lexically dependent; CLI would thus receive a lexical boost when a high-frequency competitor is being co-activated.

With regard to language dominance, our findings show that CLI occurs in the same direction for the two children regardless of their individual expressive abilities. More importantly, the magnitude of CLI appears to vary as a function of the children's dominance when it comes to their expressive abilities. Sophie's considerable accelerated acquisition of determiners in English indicates that French has a stronger impact on English than the reverse for this fairly balanced child. In contrast, Anne's delayed determiner development in French suggests that English has a stronger incidence on French for this English-dominant child. This observation is reinforced by the fact that instances of cross-linguistic transfer from English to French occur across the observation period for Anne but mainly after periods of English dominance with regard to productive skills for Sophie. The role of expressive abilities in the likelihood of CLI is consistent with the predictions made by a speech-production model where the previous activation of a word and its associated syntactic structure (in this case the presence vs. absence of a determiner before a noun) is likely to determine the strength of the competitor.

As for language exposure, the current findings cannot categorically rule out its role on the magnitude of CLI since this variable was not calculated on a monthly basis but rather for the whole observation period or whenever there was an important change of caring arrangements. If language exposure affects CLI at the determiner level, it may be considered to play a role on the direction of CLI. 
Despite the obvious generalization limitations induced by the small number of occurrences of determiners in our longitudinal corpus of two French-English bilingual children, this study confirms trends observed in the literature, such as the reduced asymmetric rate of determiner development in the context of a Romance-Germanic language pair. Crucially, these preliminary results offer new insights into the language-internal mechanisms and language dominance constraints that affect CLI. While neither the structural overlap nor the economy hypothesis can predict all the instances of CLI at the determiner level, our findings are consistent with a processing account interpretation of CLI. This study calls for large-scale experimental studies to verify the new hypothesis emerging from our corpus data with regard to the effect of productive measures of language dominance on the magnitude of CLI, as well as to whether individual measures of language exposure affect CLI at the determiner level.

\section{References}

Abu-Akel, A., Bailey, A., \& Thum, Y.-M. (2004). Describing the acquisition of determiners in English: a growth modeling approach. Fournal of Psycholinguistic Research, 33(5), 407-24.

Argyri, E., \& Sorace, A. (2007). Crosslinguistic influence and language dominance in older bilingual children. Bilingualism: Language and Cognition, IO( I), 79-99.

Bassano, D. (I998). L'élaboration du lexique précoce chez l'enfant français: structure et variabilité. Enfance, 5I(4), I23-53.

Bloom, L. ( 1970$)$. Language development: form and function in emerging grammars. Cambridge, MA: MIT Press.

Brown, R. (г973). A first language : the early stages. Cambridge, MA: Harvard University Press.

Cattani, A., Abbot-Smith, K., Farag, R., Krott, A., Arreckx, F., Dennis, I., \& Foccia, C. (20I4). How much exposure to English is necessary for a bilingual toddler to perform like a monolingual peer in language tests? International Fournal of Language $\Xi^{\circ}$ Communication Disorders, 49(6), 649-7 I.

Chierchia, G. (1998). Reference to kinds across language. Natural Language Semantics, 6(4), $339-405$.

De Cat, C. (20I I). Information tracking and encoding in early $\mathrm{L}_{\mathrm{I}}$ : linguistic competence vs. cognitive limitations. Fournal of Child Language, 38(4), 828-60.

De Cat, C. (2013). Egocentric definiteness errors and perspective evaluation in preschool children. Fournal of Pragmatics, 56, 58-69.

De Houwer, A. (2009). Bilingual first language acquisition. Bristol: Multilingual Matters.

Fernández Fuertes, R., \& Liceras, J. M. (2010). Copula omission in the English developing grammar of English/Spanish bilingual children. International Fournal of Bilingual Education and Bilingualism, I3(5), 525-5 I.

Garton, A. (1983). An approach to the study of determiners in early language development. Fournal of Psycholinguistic Research, I2(5), 5 I 3-25.

Granfeldt, J. (2000). The acquisition of the determiner phrase in bilingual and second language French. Bilingualism: Language and Cognition, 3(3), 263-80.

Hartsuiker, R. J., \& Pickering, M. J. (2008). Language integration in bilingual sentence production. Acta Psychologica, I28(3), 479-89.

Hervé, C., Serratrice, L., \& Corley, M. (2016). Dislocations in French-English bilingual children: an elicitation study. Bilingualism: Language and Cognition, I9(5), 987-ı 000. 
Hsin, L., Legendre, G., \& Omaki, A. (2013). Priming cross-linguistic interference in SpanishEnglish bilingual children. Paper presented at the Proceedings of the 37 th Annual Boston University Conference on Language Development.

Hulk, A. (2004). The acquisition of the French DP in a bilingual context. In P. Prévost \& J. Paradis (Eds.), The acquisition of French in different contexts: focus on functional categories (pp. 243-74). Amsterdam: John Benjamins.

Hulk, A., \& Müller, N. (2000). Bilingual first language acquisition at the interface between syntax and pragmatics. Bilingualism: Language and Cognition, 3(3), 227-44.

Kail, M., \& Hickmann, M. (I992). French children's ability to introduce referents in narratives as a function of mutual knowledge. First Language, I2(34), 73-94.

Karmiloff-Smith, A. (1979). A functional approach to child language. Cambridge University Press.

Kupisch, T. (2003). The DP, a vulnerable domain? Evidence from the acquisition of French. In N. Müller (Ed.), (In)vulnerable domains in multilingualism (pp. I-39). Amsterdam/ Philadelphia: John Benjamins Publishing.

Kupisch, T. (2007). Determiners in bilingual German-Italian children: what they tell us about the relation between language influence and language dominance. Bilingualism: Language and Cognition, Io( (1), 57-78.

Kupisch, T., \& Pierantozzi, C. (2010). Interpreting definite plural subjects: a comparison of German and Italian monolingual and bilingual children. In 34th BUCLD (pp. 245-54). Somerville: Cascadilla Press.

Liceras, J. M., Fuertes, R. F., \& de la Fuente, A. A. (2012). Overt subjects and copula omission in the Spanish and the English grammar of English-Spanish bilinguals: on the locus and directionality of interlinguistic influence. First Language, 32(1/2), 88-I I 5 .

Maratsos, M. (1974). Preschool children's use of definite and indefinite articles. Child Development, 45(2), 446-55.

Müller, N. (г994). Gender and Number agreement within DP. In J. Meisel (Ed.), Bilingual first language acquisition: French and German grammatical development (pp. 53-88). Philadelphia/Amsterdam: John Benjamins Publishing.

Nicoladis, E. (2006). Cross-linguistic transfer in adjective-noun strings by preschool bilingual children. Bilingualism: Language and Cognition, 9( I), I 5-32.

Nicoladis, E. (2012). Cross-linguistic influence in French-English bilingual children's possessive constructions. Bilingualism: Language and Cognition, I5(2), 320-8.

Paradis, J., \& Genesee, F. ( I 996). Syntactic acquisition in bilingual children. Studies in Second Language Acquisition, I8(I), I-25.

Pine, J., \& Lieven, E. (I 997). Slot and frame patterns and the development of the determiner category. Applied Psycholinguistics, I8(2), I 23-38.

Prévost, P. (2009). The acquisition of French: the development of inflectional morphology and syntax in $L_{I}$ acquisition, bilingualism, and $L_{2}$ acquisition. Philadelphia/Amsterdam: John Benjamins Publishing.

Schafer, R., \& De Villiers, J. (2000). Imagining articles: what $a$ and the can tell us about the emergence of DP. In S. Howell, S. Fish, \& T. Keith-Lucas (Eds.), Proceedings of the 24 th BUCLD (pp. 609-20). Somerville, MA: Cascadilla Press.

Serratrice, L. (2005). The role of discourse pragmatics in the acquisition of subjects in Italian. Applied Psycholinguistics, 26(3), 437-62.

Serratrice, L. (2007). Cross-linguistic influence in the interpretation of anaphoric and cataphoric pronouns in English-Italian bilingual children. Bilingualism: Language and Cognition, IO (3), 225-38.

Serratrice, L., Sorace, A., Filiaci, F., \& Baldo, M. (2009). Bilingual children's sensitivity to specificity and genericity: evidence from metalinguistic awareness. Bilingualism: Language and Cognition, I2(2), 239-57.

Serratrice, L., Sorace, A., Filiaci, F., \& Baldo, M. (2012). Pronominal objects in EnglishItalian and Spanish-Italian bilingual children. Applied Psycholinguistics, 33(4), 725-5I. 
Serratrice, L., Sorace, A., \& Paoli, S. (2004). Crosslinguistic influence at the syntaxpragmatics interface: subjects and objects in English-Italian bilingual and monolingual acquisition. Bilingualism: Language and Cognition, 7(3), I 83-206.

Stevenson, R. J., \& Sims, K. M. (I993). Do young children use definite expressions for specific references. In David J. Messer \& Geofrey J. Turner (Eds.), Critical influences on child language acquisition and development ( $\mathrm{pp}$. I38-55). Basingstoke: Macmillan.

Vasilyeva, M., Waterfall, H., Gamez, P. B., Gomez, L. E., Bowers, E., \& Shimpi, P. (2010). Cross-linguistic syntactic priming in bilingual children. Fournal of Child Language, 37(5), I $047-64$.

Warden, D. A. (1976). The influence of context on children's use of identifying expressions and references. British Fournal of Psychology, 67(1), IоI-I2. 